\title{
EL MEJORAMIENTO HABITACIONAL DE LOS ASENTAMIENTOS ESPONTANEOS
}

\author{
VICTOR SAUL PELLI
}

\section{PAUTAS PARA UNA ESTRATEGIA DE SOLUCION HABITACIONAL A TRAVES DE LA VALORACION DEL HABITAT ESPONTANEO DE LOS SECTORES POPULARES}

La situación de insatisfacción de las necesidades habitacionales básicas y el acrecentamiento del problema pese al esfuerzo de sus protagonistas centrales, se manifiestan en formas que de una $u$ otra manera producen alguna reacción en los sectores que cuentan con poder o recursos para encarar su resolución; en particular aunque no exclusivamente, el sector gubernamental. Esta reacción o resonancia es el origen de todos los planes habitacionales. Pero es importante tener en claro que en cada caso puede tener diferente signo y obedecer a distintas motivaciones así como puede ser experimentada por distintos protagonistas. La reacción y las acciones de respuesta que se originen en ella pueden tener como motor, objetivos genuinos de justicia social; impulsos de solidaridad social (en las muy diversas y a veces antagónicas versiones de la noción de solidari- dad); nociones de orden y seguridad (también de muy variados signos, incluso los de autoritarismo extremo); objetivos de estética urbana; y también especulaciones sectoriales de los actores sociales externos: beneficios electorales, beneficios económicos, publicidad institucional, etc. Obviamente las soluciones habitacionales originadas en estas motivaciones o lo que es más frecuente, en complicadas combinaciones de motivaciones como éstas son profundamente diferentes entre sí como lo son también las consecuencias sociales de esas soluciones.

Pero antes de llegar a las soluciones conviene advertir que estas motivaciones empiezan a incidir en las interpretaciones o lecturas que esos agentes externos (externos en relación a la población afectada) hacen de la misma situación habitacional espontánea, con influencia directa sobre la orientación de las soluciones que luego adopten o elaboren. A esa incidencia que estas motivaciones profundas puedan tener sobre la lectura o interpretación de cada situación habitacional espontánea, convie- 
ne agregar también, el nivel de idoneidad técnica o de falta de ella con que pueden hacerse esas lecturas, cualquiera sea la motivación original.

Las situaciones habitacionales espontáneas, vistas a través de distintas lentes, reciben diversas valoraciones que en los hechos van: desde su negación o desestimación total o parcial como esquemas de solución (serían meras situaciones de desgracia que corresponde erradicar y reemplazar), hasta un reconocimiento global de su valor como forma germinal de solución, cualesquiera fueran sus insuficiencias o defectos parciales y/o instrumentales.

Los objetivos fijados para este trabajo incluyen por definición una toma de posición próxima al segundo término de esta opción y muy alejada del primero.

Los argumentos que conducen a esta toma de posición reconocen en las soluciones populares espontáneas valores como los siguientes:

\section{ASPECTOS POSITIVOS DE LAS SOLUCIONES HABITACIONALES ESPONTANEAS}

- Su naturaleza autogestionaria: que se estima positiva en su condición de marco adecuado tanto para la estricta administración de recursos como para el ejercicio de crecimiento de comunidades e individuos.

- Su manejo preciso y obviamente realista de las prioridades de los propios habitantes, diferentes en cada caso: ubicación urbana, ítems de confort, espacio habitable, vecindario, aspecto, etc.

- Su flexibilidad normativa, que por la misma condición de marginalidad resuelve de manera práctica y expeditiva la imposibilidad de respuesta a normas urbanas, de construcción o de prestación de servicios, excesivamente rigurosas.

- Su agilidad para las transacciones, y su acceso indistinto tanto al mercado formal como al informal.

- Su capacidad de derivación a los mismos beneficiarios de la acción habitacional, o a su sector social, de los beneficios secundarios de la inversión que ésta demanda (generación de trabajo, operaciones en el mercado informal de materiales y servicios, etc).

Dentro de la gran variedad de situaciones habitacionales espontáneas estos valores no se presentan con la misma intensidad ni el mismo signo en todas. Algunas de ellas, incluso, no presentan posibilidades de ser rescatadas, ni como modelos, ni como situaciones mejorables, ni como fuentes de obtención de claves de solución.

Esto da lugar a la advertencia de que la aproximación al campo de las soluciones populares con la hipótesis de su valor potencial como germen para las soluciones de apoyo institucional, sólo puede arrojar resultados serios si viene acompañada de una actitud rigurosamente crítica y de una 
particular disposición para ver los rasgos esenciales de cada proceso. Esto vale tanto para los rasgos positivos como para los negativos.

Las propuestas de solución habitacional que se generan a partir del reconocimiento y la reelaboración crítica de los valores, potenciales o tangibles, de las soluciones espontáneas, se desarrollan en dos grandes líneas:

1. Procedimientos de producción de situaciones habitacionales nuevas, con incorporación de modos y esquemas propios de las soluciones espontáneas.

2. Procedimientos de producción de situaciones habitacionales satisfactorias a partir del reconocimiento de valor, y mediante el mejoramiento integral, de las situaciones ya existentes y resultantes de las acciones populares espontáneas incorporando sus modos de resolución.

La primera de esas dos líneas, de indudable riqueza, queda también fuera del marco de este trabajo, que se circunscribirá, a partir de aquí, al desarrollo de la segunda, dedicada a la modalidad de acción a la que se asignará aquí el nombre genérico de mejoramiento. (1)

\section{EL MEJORAMIENTO DE ASENTAMIENTOS POPULARES ESPONTANEOS, URBANOS Y RURALES}

La modalidad de acción habitacio- nal que aquí se denominará mejoramiento, se caracteriza por las pautas que ya se señalaron y que se repetirán aquí para mayor precisión. A ellas se agregarán otras dos, de carácter limitativo, que tienen por fin el ajuste del campo de atención de este trabajo a los objetivos de colaborar con la evolución de las condiciones de vida y la situación social de los sectores populares.

\section{Pautas de caracterización de las acciones de mejoramiento}

1. Reconocimiento de valor (económico, social, cultural) a la situación habitacional preexistente de los pobladores que van a ser asistidos.

2. Solución habitacional lograda mediante la transformación de esa misma situación (optimización, regularización, corrección, etc).

3. Situación habitacional preexistente en un nivel de insatisfacción total o parcial de necesidades habitacionales básicas.

4. Destino de la solución habitacional a los mismos usuarios previos de la situación habitacional que se transforma.

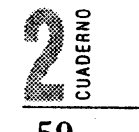

(1) El Uso de este término no está generalizado ni unificado. En los textos sobre el tema, incluso resoluciones oficiales, suelen usarse, con diferencias de matices en sus significados, las palabras: mejoramiento, consolidación, regeneración, habilitación, rehabilitación, urbanización, acondicionamiento, radicación. De modo que el significado que se adjudica aquí a algunas de ellas será una convención válida sólo para este texto, que intenta aproximarse a los usos más generalizados. 
Estas dos últimas pautas implican dejar fuera del estudio numerosos trabajos que, en otros contextos y en relación a otros objetivos, pueden ser considerados valiosos, como por ejemplo: remodelación y refacción de viviendas o conjuntos habitacionales que se encuentran en un nivel aceptable de confort, para actualizarlos estilísticamente o tecnológicamente, o para incrementar su rentabilidad; rehabilitación de edificios o sectores de valor histórico, para darles destinos de interés turístico o para aplicarlos a una operación comercial que solvente los gastos de rehabilitación, o en general, para destinarlos a sectores socialmente más favorecidos que el de los ocupantes previos; planes de renovación urbana, consistentes por definición en desalojar un sector de ocupantes no solventes para remodelarlo, levantar su nivel de calidad y destinarlo a ocupantes solventes, etc. En una definición más amplia y abarcadora estas obras también pueden denominarse "mejoramiento", pero su exclusión de este trabajo es parte inicial de la tarea de precisar cuál es el mejoramiento que contribuye a la evolución de los sectores populares y cuáles son los instrumentos metodo-

(2) Aspectos tales como: una relación contractual aberrante con el propietario de un departamento alquilado a bajo precio; dificultades para lograr entre los habitantes de un asentamiento un entendimiento para la distribución de las tierras; excesivo costo de transporte entre un asentamiento y los lugares de trabajo o de servicios sociales; problemas de estabilidad del suelo; malos servicios en el lugar del asentamiento; etc. lógicos adecuados a ese mejoramiento.

A esas cuatro pautas que tienen el propósito de dar una definición básica a los trabajos de mejoramiento que pueden interesar en un proyecto de estas características se agregan las siguientes reflexiones, como un avance hacia la tarea de conocerlos y evaluarlos.

- El empleo de la expresión "situaciones habitacionales" pone énfasis en el objeto real del mejoramiento. El énfasis se hace necesario para corregir la noción muy arraigada que confunde "vivienda" con el edificio donde ésta se constituye y "mejoramiento de vivienda", con el mejoramiento del edificio. El punto crítico de la situación habitacional de una familia puede encontrarse en diversos aspectos no directamente relacionados con la calidad del edificio (2). Dicho de otro modo, la calidad o el tamaño del edificio no siempre son la causa de una situación habitacional crítica. El mejoramiento consecuentemente podrá darse a través de una serie de acciones que no pasan de manera prioritaria o excluyente o de ninguna manera por el mejoramiento cualitativo o cuantitativo de la edificación. Una vez hecho ese señalamiento corresponde compensarlo dejando en claro que la mala calidad o la insuficiencia en volumen o superficie del edificio - vivienda también pueden ser el punto crítico de una situación habitacional. Pero conven- 
dría que eso se determinara como resultado de un diagnóstico global de la situación.

- El mejoramiento es esencialmente una transformación que implica una asignación de valores: de signo negativo a la situación existente y de signo positivo a la situación meta de la modificación; es decir el estado en que quedará el asentamiento luego de la acción. Qué se considera negativo y cuáles son las metas de satisfacción puede parecer obvio a cada actor social (habitantes, propietarios, técnicos, estado, etc.) y a cada observador en cada caso. Pero tanto la experiencia como la evaluación teórica pueden demostrar que esas apreciaciones dificilmente coincidan y que en numerosos casos pueden ser antagónicas.

Dado que en las acciones de mejoramiento y en particular en aquellas con intervención institucional opera más de un actor (entendido no en carácter individual sino como representante de un sector social) cabe considerar como una parte estructural del proceso de mejoramiento aquella instancia en la que se confrontan o enfrentan las diferentes valoraciones y motivaciones y de la que surge como resultado la definición real (no siempre coincidente con la declarada y oficial) de métodos, metas y objetivos que será la base de la acción. La experiencia indica también que esa instancia de confrontación dificilmente es un único momento en el tiempo: en la práctica puede ser una larga sucesión de negociaciones o una tarea metodológicamente prevista o una confrontación agresiva y prolongada o una sucesión de etapas en las que las cosas pasen de uno de estos estados a otro.

Estas observaciones pueden explicar que una misma acción sea vista como exitosa por algunos de los actores (o por un observador externo) y como fallida o errada por otros.

En este nivel de análisis si algo no anduvo bien para alguien puede no ser el resultado de una falla técnica sino de algo así como una derrota en la confrontación de apreciaciones (vale decir de valores e intereses) y de metas entre los distintos actores.

Como en tantos campos, en las acciones de mejoramiento no es posible contar con una escala universal de medición. Para el observador, que puede ser tanto uno de los propios actores como un agente externo, existe la posibilidad de aplicar una escala de medición (evaluación) de lo que se hizo o de lo que se está haciendo compatible con la que de hecho surgió como una síntesis de los encuentros o confrontaciones en que los actores llegaron a definir lo que se iba a hacer $y / o$ como se iba a hacer, $u$ otra que permita evaluar tanto lo proyectado como lo realizado desde una visión global determinada de la sociedad y de su desenvolvimiento, consecuente con las motivaciones e intereses a que responde el observador.

Consecuentemente: ni es posible 
hablar de la bondad intrínseca de cualquier acción de mejoramiento que haya cumplido con sus objetivos y metas de partida ni es tampoco posible suponer la existencia de pautas de aceptación universal que permitan reconocer a una acción de mejoramiento como positiva y a otra como negativa.

Corresponde definir las condiciones que en una acción de mejoramiento y para un participante de la acción (que podría ser el equipo técnico de apoyo), permitan garantizar que la acción se oriente hacia la evolución social de los habitantes y poner en claro cual es para ese participante el sentido de esa evolución.

La definición de esas condiciones debe ser el resultado de un trabajo organizado de intenso intercambio y elaboración y compromiso grupal. No puede ser sustituida por la propuesta de una persona. Lo que sigue tiene en consecuencia sólo el carácter de notas preliminares y aporte personal para esa tarea de elaboración colectiva.

\section{CONDICIONES DE COMPATIBILIDAD ENTRE UNA ACCION DE MEJORAMIENTO Y LA PROMOCION SOCIAL DE LOS HABITANTES}

- El diagnóstico de la situación habitacional que hace de punto de partida de la acción de mejoramiento debe tener como componente predominante la apreciación directa de los propios habitantes.

- Pocas veces la relación entre el pro- blema y los recursos disponibles para resolverlo es satisfactoria y se hace indispensable una escala de prioridades. En la elaboración de esta escala también el componente predominante debe ser la apreciación de los propios habitantes.

- Una acción de mejoramiento, por la intensidad con que altera y dinamiza la vida de los habitantes, tiene para con ellos un papel fuertemente inductor: si su participación en todas o la mayoría de las instancias de la acción (diagnóstico, gestión, proyecto, administración, ejecución, evaluación) es activa y protagónica, funciona como una experiencia de educación, aglutinamiento y crecimiento; si su participación es pasiva y subordinada, funciona en el mejor de los casos, como una acción que beneficia sólo a través de una transferencia de bienes y servicios (es decir como una acción de beneficencia); y en el peor como una experiencia adormecedora y exacerbadora de hábitos de dependencia de "ayudas" externas.

Debería considerarse como componente esencial de una acción de mejoramiento que merezca una evaluación positiva la participación activa y protagónica de los habitantes en todas o la mayoría de las instancias de la acción.

- Como condición para una participación activa y protagónica, la relación entre los actores intervinientes, representantes de distintos sectores sociales, no debe ser una réplica de la relación dada para esas mismas 
personas en la estructura social existente en la que a los habitantes del asentamiento les cabe una posición de sometimiento, dependencia y/o marginación. En la acción de mejoramiento esa relación puede y suele repetirse aún en los casos presentados como "participativos" en formas sutiles de "acatamiento del criterio del que sabe más", "no discutirle al que pone la plata", limitación de la participación del habitante al aporte de su fuerza física o subordinación a modelos tomados de sectores sociales dominantes.

- En coherencia con los puntos precedentes, la tecnología a aplicar, tanto en lo que hace a las obras físicas como en lo relacionado con acciones legales o administrativas, mecanismos de financiación y recupero, y técnicas de organización y promoción comunitaria debe seleccionarse o diseñarse, e implementarse, de manera de colaborar con los otras condiciones 0 , al menos, no interferir con ellos. Es decir que deben ser técnicas que:

- Puedan ser comprendidas, interpretadas y, si corresponde, implementadas y administradas por los habitantes. (3)

- Generen productos (obras físicas, estructuras organizativas, etc) armonizables con el esquema cultural que los habitantes se propongan y puedan alcanzar con el mejoramiento. (4)

- No sean inductoras o generadoras de esquemas de relación en los que a los habitantes les quepa un rol de sometimiento, marginación o dependencia.

Dada lo variedad de factores que intervienen en la gestación y en la práctica de una acción de mejoramiento, dificilmente se encontrarán casos que respondan plenamente a este conjunto de condiciones. Pero en cualquier acción de mejoramiento será posible detectar su tendencia a asimilarse a ellas o a distanciarse, incluso a oponerse. Sin duda, esto también ocurrirá en un caso por comenzar, aún cuando alguno de los actores (el equipo técnico de apoyo, por ejemplo) se proponga respetar y aplicar a fondo estas condiciones. Un procedimento de mejoramiento del habitat popular es, como se dijo antes, un campo de confrontación y de negociación entre todos los actores, presentes y ausentes. Estas condiciones, en ese campo, no se aplicarán automáticamente: serán, en muchos casos, sólo el bagaje conque algunos actores se incorporarán a la negociación.

(3) Esto no debe leerse como limitación a técnicas vernáculas o elementales aunque éstas se incluyen. Las técnicas más avanzadas, lo que se denomina "tecnología de punta", también suelen cumplir con este requisito.

(4) Es interesante tener en cuenta esta visión de la orientación de la solución hacia los esquemas culturales de los habitantes: es muy común el criterio, entre los técnicos, de orientar las soluciones hacia los esquemas culturales actuales o incluso previos (por ejemplo, cultura rural) de los habitantes, sin tener en cuenta que los esfuerzos de consolidación habitacional vienen generalmente acompañados de una fuerte voluntad, por parte de los pobladores, de modificar sus pautas adoptando más o menos gradualmente las de la sociedad urbana consolidada, a la que quieren integrarse.

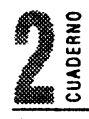

63 